\title{
Steering committee for Eastern Mediterranean Region drug regulatory authorities ${ }^{1}$
}

Citation: Steering committee for Eastern Mediterranean Region drug regulatory authorities. East Mediterr Health J. 2019;25(8):591-592 https://doi. org/10.26719/2019.25.8.591

Copyright @ World Health Organization (WHO) 2019. Some rights reserved. This work is available under the CC BY-NC-SA 3.0 IGO license (https:// creativecommons.org/licenses/by-nc-sa/3.o/igo).

\section{Introduction}

Effective regulation of medicines and medical products promotes and protects public health. Regulation aims to ensure the quality, safety and efficacy of medical products (medicines, vaccines, diagnostics, medical devices, etc.) through enforcement of legislations, norms and standards. National regulatory authorities (NRAs) for medical products, with adequate capacity, can efficiently play this role.

The World Health Organization (WHO) Regional Office for the Eastern Mediterranean organized the first Eastern Mediterranean Drug Regulatory Authorities Conference (EMDRAC) in 1993 (1), to serve as a biennial event bringing together NRAs from the Region as well as regulatory leaders from regional and international organizations to exchange experience and share cuttingedge professional approaches and techniques spanning all core regulatory functions. At the 2018 Eastern Mediterranean Drug Regulatory Authorities Conference (EMDRAC 2018) held in Salalah, Oman, in July 2018 (2), it was agreed by NRAs to establish a steering committee to meet annually for capacity-building, collaboration, harmonization and monitoring of the EMDRAC recommendations. The steering committee would be composed of selected directors of NRAs in the Region in order to enhance cooperation between regulatory authorities in the Region; identify and plan capacitybuilding activities related to the regulation of medical products; exchange relevant information on safety and quality of medical products; promote effective regulation and regulatory mechanisms of medical products; review progress made towards implementation of EMDRAC and International Conference of Drug Regulatory Authorities (ICDRA) recommendations; andpromote research on the regulation of production, distribution and use of medicines, vaccines and medical products.

Subsequently, the WHO Regional Office for the Eastern Mediterranean organized the first meeting of the Steering Committee for Eastern Mediterranean Drug Regulatory Authorities from 9 to 10 April 2019, in Amman, Jordan (3). The meeting was attended by representatives from 11 Member States of the Region (Afghanistan, Bahrain, Egypt, Iraq, Jordan, Kuwait, Morocco, Oman, Palestine, Saudi Arabia and Syrian Arab Republic).
The WHO Secretariat comprised staff members from headquarters, the regional and country offices.

The objectives of the meeting were to:

- develop and agree on terms of reference for the Steering Committee;

- discuss regional and national challenges encountered by NRAs in the regulation of medical products; and

- facilitate further collaboration between NRAs and promote regulatory harmonization initiatives.

\section{Summary of discussions}

Challenges in the regulation of medical products in the Region were discussed in group work sessions. Identified challenges included: lack of coordination between NRAs at regional level; absence of well-trained human resources; weak registration systems (especially for medical devices, vaccines and other biologicals); weak pharmacovigilance systems; poor implementation of good manufacturing practices; weak post-marketing surveillance and inspection; poor quality control laboratories; and lack of proper pricing control systems.

The terms of reference of the Steering Committee were discussed. It was agreed that the Committee will act as an advisory body to enhance capacity-building, collaboration, harmonization and networking among NRAs in Member States of the Region, and to prepare and monitor implementation of EMDRAC recommendations. Membership of the Committee will be voluntary for designated representatives from Member States (head of the NRA or his/her alternative) which wish to be represented. The Steering Committee will be composed of nine members, serving for a period of two years and for a maximum of two terms. The chair and vice-chair will serve on a rotational basis among countries, and will be selected upon mutual agreement by members of the Steering Committee. Other Member States of the Region can attend Steering Committee meetings as observers. Guests and experts can be invited to Steering Committee meetings, as needed. The WHO Regional Office for the Eastern Mediterranean will serve as secretariat to the Steering Committee.

This report is extracted from the Summary report on the meeting of the Steering Committee for Eastern Mediterranean drug regulatory authorities, Amman, Jordan, 9-10 April 2019 (http://applications.emro.who.int/docs/IC_Meet_Rep_2019_EN_23814.PDF?ua=1). 


\section{Recommendations}

\section{To the Steering Committee}

- Serving as a platform for information sharing, convergence and cooperation in the Region.

- Working towards obtaining and building commitment from Member States in the area of regulatory systems strengthening.

- Consulting with NRAs on topics of interest for the EMDRAC, and subsequently approving the agenda.

- Promoting collaboration between Member States, including exchange of information and expertise on existing requirements and regulations.

- Promoting harmonization of the regulatory guidelines among Member States.

- Facilitating the implementation of EMDRAC recommendations by NRAs.

- Facilitating signing memoranda of understanding (MoUs) between NRAs for exchange of information and technical assistance for needed services for strengthening regulatory systems.

- Holding face-to-face meetings at least twice a year, and virtual meetings (via teleconference) every four months, or as the need arises.

\section{To WHO}

- Providing technical and administrative support to the Steering Committee.

- Facilitating and organizing face-to-face and virtual meetings of the Steering Committee

- Developing, managing and updating advocacy and information materials.

- Ensuring reporting on activities of the Steering Committee and disseminating the information to all Member States.

- Developing a networking tool (EZcollab or SharePoint) for the heads of NRAs in the Region to share all information related to the regulation of medical products.

\section{References}

1. World Health Organization Regional Office for the Eastern Mediterranean (WHO/EMRO). Drug regulatory authorities of the Eastern Mediterranean Region - report on the joint WHO/DSE regional meeting, Tunis, Tunisia, 2-8 November 1993. Alexandria:WHO/EMRO; 1995 (https://apps.who.int/iris/bitstream/handle/10665/258633/who_em_pts_165_e_l_en.pdf?sequence=1\&isAllowed=y).

2. World Health Organization Regional Office for the Eastern Mediterranean (WHO/EMRO). Summary report on the Eastern Mediterranean drug regulatory authorities conference (EMDRAC). Cairo: WHO/EMRO; 2019 (http://applications.emro.who.int/docs/ IC_Meet_Rep_2019_EN_22324.pdf?ua=1).

3. World Health Organization Regional Office for the Eastern Mediterranean (WHO/EMRO). Summary report on the meeting of the Steering Committee for Eastern Mediterranean drug regulatory authorities. Cairo: WHO/EMRO; 2019 (http://applications. emro.who.int/docs/IC_Meet_Rep_2019_EN_23814.PDF?ua=1). 